\title{
LA TRAGEDIA FRAGMENTARIA GRIEGA Y LAS VERSIONES DEL MITO DE ALCMEÓN
}

\author{
Lidia Gambón \\ Universidad Nacional del Sur \\ lgambon@uns.edu.ar
}

\begin{abstract}
Partiendo de la vitalidad del estudio de la tragedia griega fragmentaria en los últimos decenios, el presente artículo remarca su valor con relación a los textos supérstites del pasado, y se detiene en el análisis del tratamiento trágico del mito de Alcmeón. Su profusa presencia en la escena del período clásico contrasta con el hecho de que no ha sobrevivido, sin embargo, ninguna obra completa. Pese a la escasez de los fragmentos y los problemas textuales y contextuales que se plantean, el relevamiento lexical de las versiones sofocleas y euripideas permite dar cuenta de los hitos fundamentales de la biografía trágica de Alcmeón. Revela, asimismo, la necesidad de una mirada inquisidora en torno a la memoria de las historias conservadas, y de aquellas que se han perdido.
\end{abstract}

Tragedia griega / Fragmentos / Alcmeón / Sófocles / Eurípides

\section{THE FRAGMENTARY GREEK TRAGEDY AND THE MYTH OF ALCMEON}

Starting from the vitality that the study of the fragmentary Greek tragedy has acquired in the last decades, the paper emphasizes its value in relation to the surviving texts of the past, and analyzes the tragic treatment of the myth of Alcmeon. Its profuse presence in the classical drama contrasts, however, with the fact that no complete work has survived. Despite the scarcity of fragments and the textual and contextual problems posed by this, the lexical survey of Sophocles and Euripides' fragmentary plays shows us the fundamental milestones of the Alcmeon's tragic story and reveals the need for an inquisitive look around the memory of the preserved histories and of those that have been lost.

Greek Tragedy / Fragments / Alcmeon / Sophocles / Euripides 
A Greek tragic fragment has a curious status; it is a tiny textual window on a multimedial ancient event, a few words hacked out of both their performance environment and their literary context, to speak

-sometimes eloquently-over the centuries. The strange journey across time taken by the physical fragments of tragedy -their survival - also resonates with the idea of the survivor of trauma that is central both to Greek tragedy and to our contemporary sense of historical identity. (HALL, 2010: 337)

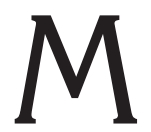

ucho se ha avanzado en el conocimiento de la tragedia fragmentaria desde que en 1967 Thomas B.L. WeBster señalara, respecto del trágico del que han sobrevivido más fragmentos, que lo único que se había escrito en la primera mitad del s. XX sobre este tema era el apéndice a las obras perdidas de Gilbert Murray en The Athenian Drama III. Euripides (1906). WEBSTER declaraba entonces (1967: 1): "Reconstructing lost plays is a dangerous business, and I have therefore thought it essential to give all the evidence (or at least to refer to places where the evidence can be found)". También August Nauck (1964), años antes, había exhortado, en su edición de los TGF, a la prudencia y al sentido crítico para quien trabajara con fragmentos. Entre estas valoraciones, empeñadas en subrayar los escabrosos límites planteados por el propio objeto, y las de autores como Sophie Mills (2003), Edith Hall (2010), o Mattew Wright (2016) pareciera mediar un abismo, y no únicamente la distancia cronológica de poco más de medio siglo que las separa ${ }^{1}$.

Sin embargo, sin desestimar los reclamos de cautela a que han alentado tradicionalmente filólogos y editores - reclamos que reafirman su perdurable vigencia (cf. WRIGHT, 2016: xxV-xxvi) - lo cierto es que afortunadamente hoy el material fragmentario se insinúa como un campo fecundo, que ha ampliado grandemente el horizonte del drama en particular, $\mathrm{y}$, podríamos decir, el de otros géneros también, en virtud de una esencia - la ausencia, la fragmentación - que ha sido vinculada a los rasgos de la cultura postmoderna ${ }^{2}$. Para ello, y solo considerando la tragedia, basta ver en la actualidad el número de ediciones, re-ediciones, estudios sobre

1 Al reflexionar sobre la tragedia fragmentaria de Sófocles, MILLS concluye: "Even if it cannot tell us everything we would like to know, however, the study of fragmentary tragedy can sometimes offer a perspective that a study limited to extant tragedy denies us" (2003: 220). Para HALL, remitimos al capítulo al que pertenece el pasaje citado en el epígrafe.WRIGHT acierta al subrayar la diferencia de perspectiva que demanda la aproximación al estudio de la tragedia fragmentaria, una perspectiva de algún modo más cercana a la arqueología que a la filología: "In a sense, the fragments and testimonia are not texts to be read so much as evidence to be weighed and sifted" (2016: xxiv).

2 Cf. Most (2009); Wright (2016: x-xi). 
material recientemente descubierto, trabajos de índole filológica específicos y generales, sin olvidar los encuentros destinados a estimular la discusión sobre este asunto, y las consiguientes importantes publicaciones que se derivaron de ellos ${ }^{3}$.

El tema, pues, se ha ganado ya por estos días un lugar indiscutible aun en los manuales introductorios del género, y va ganando terreno, asimismo - aunque con considerable menos apremio-, en el acceso a traducciones ${ }^{4}$. No solo la consolidación de nuevas disciplinas (epigrafía, papirología, paleografía, antropología) ha representado un estímulo para el abordaje de un material reconocidamente complejo, sino incluso nuevas perspectivas en torno a su recepción, las que han impulsado el estudio a fronteras que hoy se extienden más allá del campo estrictamente filológico ${ }^{5}$.

Tan claro como la vitalidad que ha cobrado el estudio del material fragmentario en los últimos decenios lo es el presupuesto que lo sostiene: el hecho de que la tragedia griega poseyó una envergadura literaria y una presencia social mayor de lo que suele atribuirse deductivamente por las obras conservadas de los grandes trágicos ${ }^{6}$. El marco cronológico de desarrollo del género, con límites difusos en cuanto a su finalización, es un

3 Con relación a este último punto, mencionamos e.g. Sommerstein (2003), derivado del encuentro en Nottingham (Centre for Ancient Drama and its Reception, University of Nottingham, 2000), McHaRdY-RoBson \& HARVEY (2005), derivado del encuentro en Exeter (University of Exeter, 1996). Para una historia del estudio del material fragmentario desde el Renacimiento hasta el último siglo, y especialmente con relación a Eurípides, cf. JouAN E Van Looy (1998) y McHardy, Robson \& Harvey (2005:7-48).

4 Sobre la presencia del tópico en los manuales del género, cf. e.g. GREGORY (2005); HALL (2010). En lo que refiere a las traducciones, el tema es aún una deuda pendiente en español, en que, de modo completo, solo contamos con la traducción de los fragmentos de Sófocles y de Esquilo (BCG).

5 En los últimos años la tragedia fragmentaria ha devenido terreno fértil no solo para traductores, sino también para escritores y productores teatrales, que se han atrevido a "reconstruir" los dramas en nuevas performances, integrando las propias conjeturas ala puesta en escena e interpretación de la obra. Un ejemplo es la contribución de David Wiles al volumen Lost Dramas of Classical Athens (WILES, 2005: 189-207), en que el editor ofrece su versión de Hipsipila. Cf. HALL (2010: 328-346), sobre performances modernas inspiradas en obras fragmentarias sofocleas y euripideas (Tereo, Alcmeón en Corinto, Hipsipila). Una importante iniciativa en este campo viene desarrollando desde 2007 el profesor Anthony Stevens (Program at the International Center for Hellenic and Mediterranean Studies, College Year of Athens), quien defiende la posibilidad de performances actuales de la tragedia fragmentaria, y el sentido de experimentar con fragmentos trágicos (se puede consultar, al respecto, el sitio web del autor:<http://lostgreekplays.com/>).

6 Esta envergadura ya fue defendida por Lucas DE Dıos (1990) en un temprano artículo en que señalaba el contraste entre el escaso tratamiento del material trágico (con excepción de los tres poetas canónicos) y la envergadura del género en el s. V a.C. y posteriormente. Dicha envergadura se funda, según el estudioso, en cuatro puntos fundamentales: a) la importancia de la actividad teatral en la cultura griega; b) la repercusión de la tragedia en 
claro índice de la envergadura que tuvo en la Antigüedad el drama: la tragedia, que aparece en Atenas de la mano de Tespis, tiene ya forma literaria en las últimas décadas del s. VI a.C., y su existencia, mucho más larga que las vidas de sus tres grandes figuras (Esquilo, Sófocles, Eurípides), traspasa la barrera del siglo IV a.C.-- "the first flush of tragedy's phenomenal spread" (TAPLIN, 2007: 22) — y se extiende, con gran auge, durante los siguientes siglos?.

De esta larga vida, solo nos han quedado, sin embargo, algunos fragmentos; en el mejor de los casos, estos fragmentos son de una extensión importante y constituyen una pieza entera. Pero no debemos olvidar que, incluso así, se trata de textos igualmente mutilados, despojados de su contexto performativo (música, danza, máscaras, aspectos diversos de la competencia político-religiosa que les daba marco). Y si aceptamos la irrefutable premisa de que todo estudio del pasado está condenado per se a ser un estudio de los fragmentos supérstites de ese pasado, la veracidad de esta afirmación se nos confirma más aún con el drama en general (y la tragedia en particular), hasta ponernos frente a la evidencia de que todo estudio sobre este género es al fin y al cabo, por esencia, el estudio de un corpus fragmentario (SOMmERSTEIN $\&$ TAlBoy, 2006: xxiii). Pues su objeto, como se describe en el epígrafe que hemos elegido, es apenas el sobreviviente de un trauma.

Abordar el tema de la tragedia fragmentaria no ofrecería, pues, en un sentido, diferencias esenciales en cuanto a la naturaleza del objeto. Y sin embargo, es preciso no menospreciar y tener presentes siempre los problemas que plantea tal objeto. Por un lado, como se ha reconocido, el problema metodológico ${ }^{8}$ : lo arduo del trabajo con los fragmentos reside no solo en los múltiples y complejos aspectos a tener en cuenta (filológicos, culturales, sociales, históricos, etc.), sino en la capacidad que demanda, para quien lo emprenda, de aprender a sortear los escabrosos límites entre la coincidencia y la complementariedad con el material de las obras completas conservadas.

la literatura posterior; c) la relevancia del género como fuente de tratamiento del mito; d) el influjo sobre la literatura trágica latina.

7

La cuestión de los límites es problemática, compleja, y sin dudas arbitraria. Para CROPP (2005), la centralidad de la tragedia en la vida cultural ateniense se prolonga hasta la desintegración de la democracia bajo el dominio macedonio (322 a.C.). No obstante, una inscripción encontrada en la base de una estatua (IG II2 3157 = Did. B 14 Snell) testimonia que en pleno siglo I d.C. se representó una tragedia nueva en las grandes Panateneas. Así, no faltan autores que llevan los límites del género hasta fines de la Antigüedad, por la envergadura de la actividad teatral durante el período imperial. Considerando el lugar en el proceso de recepción, REVERMANN (2010) llega incluso a postular el confín en la Edad Media. El problema metodológico fue señalado tempranamente por autores como LENS TuERO (1980), y más recientemente, del Rincón SÁnchez (2007). 
Por otro lado, el más esencial, el problema que se relaciona con la índole misma de la fuente, una fuente a la que podría definirse como el arte de la ausencia" (BALMER: 2013) ${ }^{9}$. Ausencia del contexto, por el escaso conocimiento de aspectos de la vida de los antiguos poetas, y la visión "mitologizada" que de ellos nos ha transmitido la Antigüedad; ausencia del texto, que nos ha llegado en proporciones muy diversas para las distintas obras, y para los distintos poetas trágicos. Pero, como la otra cara de una misma moneda, en la dinámica complementaria de la memoria y el olvido, de lo perdido y lo conservado, los fragmentos, podríamos decir —coincidiendo con el profesor Anthony STEVENS ${ }^{10}$ - implican siempre dos historias: la historia de la completud de lo que alguna vez fue, y la historia de la pérdida, una indivisible de la otra, incomprensible sin ella.

\section{Un personaje entre la memoria y el olvido}

Apelando a esta indivisibilidad entre la completud y la pérdida y a los interrogantes que nos plantea es que nos detendremos aquí en una historia singular, de profusa presencia y larga vida sobre todo en la tragedia, pero hoy infortunadamente apenas rememorada: la historia de Alcmeón. Pocas historias trágicas reúnen este carácter de haber sido tan profusamente recordadas primero y al mismo tiempo tan largamente olvidadas después, un hecho más llamativo aún si se tiene en cuenta la riqueza dramática del motivo de la guerra contra Tebas. Ello determina que, de manera inversamente proporcional al prestigio teatral que tuvo en el período clásico, Alcmeón sea apenas hoy más que un nombre.

Hijo mayor de Anfiarao, Alcmeón es uno de los escasamente recordados Epígonos. Su padre había tomado parte en la expedición de los Siete, en la famosa guerra entre Argos y Tebas, aun conociendo como adivino que estaba destinado a morir en la contienda. Precisamente por ello, Anfiarao había tratado de persuadir a su cuñado Adrasto, rey de Argos, de no tomar parte en ella, sometiéndose desde un comienzo al arbitraje inapelable de su esposa Erifila para dirimir cualquier cuestión conflictiva ( FrGrH 12 F 29 de Asclepíades; Apoll. Bibl. 3.6.2). Pero Polinices había dado a la hermana de Adrasto el collar de Harmonía, y esta, pese a la prohibición de Anfiarao, había recibido el regalo a cambio del cual persuadió a su esposo de participar en la expedición. Conociendo su muerte, Anfiarao ordenó en venganza a su/s hijo/s (Alcmeón, o Alcmeón y Anfíloco) matar a su madre y atacar Tebas por segunda vez. En esta ocasión, el oráculo garantizaba

9 Aunque la autora refiere a la poesía sáfica, resulta igualmente válida la imagen que utiliza en relación con el problema del material fragmentario: "Attempting to translate such texts, therefore, can be a little like groping at shadows in a darkened room" (BALMER, 2013: 61).

10 Ver n. 5 del presente trabajo. 
la victoria si Alcmeón iba al frente de la expedición. Después del matricidio (anterior o posterior a la expedición, según las fuentes), Alcmeón enloquece; perseguido por las Erinias y exiliado, su mito se mezcla con una serie de profusas aventuras que lo tienen como protagonista, y que giran en torno al malhadado ornamento que recibiera como obsequio Erifila y a su exilio y purificación como matricida ${ }^{11}$.

Hasta aquí, resumidamente, la historia del personaje. Esta interesó tanto a los dramaturgos que, aún en el s. IV a.C., el poeta cómico Timocles lo recuerda como paradigma del infortunio y de la representación de la locura en la escena trágica (PCG fr. 6). Pero, ¿en qué residió su riqueza, al punto de otorgarle su carácter paradigmático y concederle tan largo protagonismo dramático en la Antigüedad? Y con relación a la contracara de esta memorable presencia, ¿cuáles pudieron ser las razones de tan poderoso olvido?

\section{Infortunio de un héroe infortunado: el mito trágico de Alcmeón}

Desde la Antigüedad, la figura de Alcmeón fue asociada a la de Orestes, a pesar de que hay diferencias sustanciales en el mito, y aunque fundamentalmente solo tengan en común los dos hechos que las estigmatizaran: matricidio en venganza de un padre muerto y locura ${ }^{12}$. La opinión de Aristóteles contribuyó sin duda a cimentar esta idea. La notoriedad de Alcmeón como personaje trágico está atestiguada por el estagirita, que considera

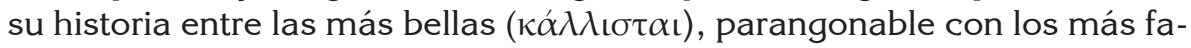
mosos conflictos familiares de Edipo u Orestes, y modelo de anagnórisis trágica (Poet. 1453a20, 1453b30-35). La tragicidad del personaje ha sido reafirmada recientemente por Carlos GARCíA GUAL (2014), para quien hay una honda dramaticidad en el destino de este héroe.

Con relación al tratamiento del mito en los autores trágicos griegos, este ha sido amplio y diverso. La saga del caudillo de los Epígonos interesó no solo a los tres grandes poetas, sino también a otros poetas me-

11 Sobre todo estos son los aspectos tratados por Sófocles en su Alcmeón, y por Eurípides en Alcmeón en Psófide y Alcmeón en Corinto. Sommerstein (2012: 28) sostiene que el poema épico Alcmeónida probablemente estuviera relacionado más con esta parte de la historia, y no con la locura y el matricidio (que corresponderían al poema épico Epígonos). Homero, por su parte, según este autor, omite deliberadamente en Odisea mencionar el matricidio de Alcmeón al hablar de Erifila. Sobre el poema épico Alcmeónida, cf. Debiasi (2015).

12 Estas diferencias pueden resumirse en dos aspectos centrales del mito en torno a los hechos que tienen en común: a) El matricidio de Alcmeón es ordenado por Anfiarao (Apolo solo se limita en la historia de Alcmeón a impulsar la ejecución de la orden paterna); b) el matricidio en Alcmeón aparece como una venganza personal, sin implicaciones dinásticas, como en el caso de Orestes. El estudio de Marie Delcourt (1959) continúa siendo hoy uno de los pocos existentes que desde una perspectiva cultural y religiosa explica la cercanía entre el mito de Orestes y el del jefe argivo. 
nores del s. V a.C. y comienzos del IV a.C., hasta llegar incluso al tardío drama latino ${ }^{13}$. También la comedia media, heredera de la tragedia, hizo de la locura de Alcmeón uno de sus motivos, según testimonia Poíesis de Antífanes (PCG fr. 189.8-11), y el ya citado fragmento de Dionysiázousai de Timocles ${ }^{14}$. Más aun, en los tres grandes trágicos la saga de Alcmeón representó, a juzgar por su recurrencia, un tema de grandes posibilidades dramáticas. Si Esquilo trató el mito en sus Epígonos (tragedia imposible de datar, pero llevada a escena con certeza en la primera mitad del siglo V a.C.), Sófocles lo tematizó al menos en tres (¿dos?) de sus obras, Alcmeón, Epígonos y Erifila, y quizás también en un drama satírico, Anfiarao ${ }^{15}$. Cualquiera sea su problemática datación, todos ellos corresponden a la segunda mitad del siglo. Eurípides, por su parte, escribió dos obras sobre este héroe: Alcmeón en Psófide (A) y Alcmeón en Corinto (B), separadas -y este es el único dato sobre el que tenemos absoluta certeza- por el período que representa para la obra conservada en el comienzo y el final de su producción ${ }^{16}$.

La presencia de Alcmeón en escena atraviesa, pues, (solo por estos autores) todo el siglo V a.C. Sin embargo, de todos los dramas apenas han sobrevivido escasos versos de Sófocles y de Eurípides; ni una simple escena ni una lista de personajes siquiera que posibiliten la "lectura" humana de este matricida, cuyo destino lo coloca, ciertamente como a Orestes, entre la responsabilidad del castigo y el castigo por su responsabilidad, en

13 Con el título de Alcmeón son conocidas al menos otras seis tragedias, que corresponden a Agatón, Timoteo, Astidamante II, Teodectes, Eváreto y Nicómaco (cf. KANNICHT, 2004: 205). También Aqueo escribió un drama satírico con este título (cf. WRIGHT, 2016: 35). La notoriedad trágica de Alcmeón se extiende al mundo latino con las versiones de Ennio y Accio, probablemente, aunque sin grado de certeza alguno (cf. MEDDA, 2001: 62-73), inspiradas en Eurípides.

14 Textos conservados en la cita de: Ateneo. Deipnosofistas, 222a-b y 223c respectivamente.

15 A la discusión de si Epígonos y Erifila constituyen dos obras diferentes o una sola consagra recientemente SOMMERSTEIN una parte del estudio introductorio a Epígonos en el segundo volumen de Sophocles. Selected Fragmentary Plays; el estudioso se inclina por la segunda de las hipótesis (2012: 34-38), aunque la evidencia —los pocos fragmentos que nos han llegado- no es concluyente para ninguna de ellas, como el mismo autor reconoce.

16

En efecto, Alcmeón en Psófide integró la tetralogía de Alcestis, el primer drama completo conservado (438 a.C.), mientras que Alcmeón en Corinto fue llevado a escena póstumamente por el hijo de Eurípides entre el año 405 y el 400 a.C., junto a las últimas obras conservadas, Bacantes e Ifigenia en Aúlide. Además de la importante evidencia que proporciona el testimonio de las hipótesis para la datación de la tragedia euripidea, otros criterios internos, como la práctica métrica de la resolución en el trímetro, permiten una datación relativamente cierta (cf. CROPP E FICK: 1985); esto no resulta posible para las obras de Sófocles, y menos aún de Esquilo, en que los fragmentos conservados son siempre sustancialmente inferiores en cantidad y extensión. 
una cadena de venganzas y traiciones que tan atractiva resultó al género trágico en el período clásico ${ }^{17}$.

Por otra parte, la historia de Alcmeón tiene importantes y controversiales elementos que provienen ya de las diversas (y paupérrimas) fuentes pretrágicas de las que nos ha llegado. Así, en los poemas homéricos, Alcmeón es mencionado solo una vez, al evocarse la muerte prematura de Anfiarao en la guerra contra Tebas (Hom. Od. 15.243-248) ${ }^{18}$. En Hesíodo, un fragmento del Catálogo de las mujeres alude al héroe, aunque sin nombrarlo (Hes. fr. 197.6 Merk-West). Las otras fuentes épicas que podrían aportarnos elementos apenas si lo hacen: el poema del siglo VI a.C. Alcmeónida, y otros de la llamada épica menor (Tebaida, Epígonos). El contenido del primero de estos poemas es apenas conocido por su mención en un escolio de Odisea; citando al mitógrafo Asclepíades de Tragilo, el escolio revela que Anfiarao ordenó la venganza a su hijo antes de partir para Tebas, y que Alcmeón enloqueció después del matricidio, pero los dioses lo liberaron de su mal por ser óoíws su crimen (Schol. Hom. Od. 11.326). De los otros poemas épicos, en cambio, los poquísimos fragmentos conservados no hacen referencia explícita alguna a Alcmeón. En cualquier caso, nuestro conocimiento de esta fuente épica, como sucede con la poesía lírica (Estesícoro. Erifila), no arroja luz por su carácter indirecto y/o reducido ${ }^{19}$.

El paralelismo con Orestes, presente en las fuentes pretrágicas, ha concentrado en torno a dos indagaciones esenciales los interrogantes sobre la fortuna de este mito en la tragedia: el matricidio y la locura. Las razones que determinaron la supervivencia de un héroe por sobre el otro en la tradición literaria posterior vinieron así a opacarse por la necesidad de indagar en la locura del héroe argivo, el modo en que ingresa al teatro y el lugar que ocupa en él, teniendo en cuenta que la manía es un tópico recurrente del género, y el matricidio, una de las más extremas formas de violación de la philía en la tragedia (cf. BELFIORE, 2000). Las respuestas, sin embargo, no han superado el terreno de la conjetura.

Con relación al matricidio, ya Marie Delcourt (1959) puntualizó en su estudio lo que parecen dos versiones diferentes, probablemente presentes en la épica menor. Según una de las variantes, Alcmeón mataría a Erifila

17 Cf. García Gual (1991) y (2014), quien defiende que el matricidio no tiene sentido pleno en el mito de Alcmeón, sino en la medida que se integra en la historia mítica a un conjunto de pactos, traiciones y venganzas familiares. Para los aspectos religiosos del matricidio de Alcmeón vinculado al de Orestes, remitimos una vez más al estudio de Delcourt (1959).

18 En Od. 11. 326 s. se menciona la presencia de la "odiosa Erifila" en el Hades.

19 Del poema épico arcaico Alcmeónida se conservan apenas un total de siete fragmentos, que han sido incluidos en el ya mencionado artículo de DeBIASI (2015); para la obra de Estesícoro solo contamos con dos fragmentos de papiro que aluden a un banquete de celebración, y cuya relación con el único fragmento conservado de Esquilo (Aesch. fr. 67 Ra [55 N]) se desconoce. Cf. Sommerstein (2012: 30-31). 
antes de atacar Tebas (esta sería la versión del poema épico Alcmeónida). Según otra versión (Tebaida, Epígonos ${ }^{20}$ ) es después de atacar Tebas que Alcmeón da muerte a su madre (solo, o con la ayuda de su hermano Anfíloco); perseguido por las Erinias y enloquecido se dirige a Arcadia primero y es purificado luego por Fegeo, rey de Psófide ${ }^{21}$. La existencia de estas dos versiones literarias parece confirmarse en una única evidencia iconográfica (LIMCs.v. Alkmaion' 3), cuyas conclusiones - expuestas por Ingrid KRAuSKOPF (1981: 551) - han sido, sin embargo, puestas en duda recientemente ${ }^{22}$. Estamos, pues, en este punto, ante un problema difícil de resolver, que poco podrá aclararnos sobre la trama y la estructura dramática de las obras, desde un problema que las precede.

Ahora bien, más allá del tratamiento pretrágico, y considerando que la reconstrucción de la trama de las tragedias perdidas solo puede plantearse con relativa certeza para los textos euripideos, resultará útil recordar en este punto dos de los axiomas metodológicos derivados en la aplicación de lo que Alan Sommerstein (2010) dio en llamar Sherlockismus, considerando que permiten vencer la frustración de la aporía a que conduce el abordaje del tema propuesto ${ }^{23}$. Si tenemos en cuenta que:

a) el tratamiento trágico de una figura heroica respeta siempre en líneas generales la macroestructura del mito del cual la historia forma parte; b) cada tragedia cuenta una historia que difiere en algún grado de otra que coincide en tratar el mismo segmento del mito;

¿qué podemos concluir de los tres trágicos con relación a la historia que nos ocupa?

20 Es la versión que sigue Apolodoro. En Apolodoro, Erifila recibe un segundo soborno (un peplo) de manos de Tersandro, el hijo de Polinices, y por ello convence a sus hijos (Alcmeón y su hermano Anfíloco) de liderar la segunda de las expediciones contra Tebas, a la que refería el poema épico Epígonos. Una vez tomada Tebas, los Epígonos envían a Delfos parte del botín de la ciudad, entre ellos, a Manto, la hija de Tiresias, personaje al que se hace referencia en Alcmeón en Corinto.

21 La versión del matricidio posterior está respaldada iconográficamente por una serie de urnas funerarias etruscas de alabastro (s. II/I a.C. - Volterra, Museo Guarnacci), en las que aparece Alcmeón dando muerte a Erifila con una corona de laurel en sus manos, indicio de su victoria sobre Tebas. Cf. LIMCs.v. 'Alkmaion' 4, 7, 8.

22 Se trata del ánfora Tirrénica del período arcaico (segundo cuarto del s. VI a.C.- Museo de Berlín), en que está representada la partida de Alcmeón con una fórmula semejante a la de la partida de Anfiarao, dejando atrás a su madre muerta, que desfallece ante un túmulo funerario detrás del cual se levanta una enorme y amenazante serpiente. Ingrid Krauskopf infiere de ello que se trataría de una representación que coloca al matricidio antes de la expedición de Alcmeón contra Tebas. Pero recientemente SommERSTEIN (2012: 30 n. 25) ha puesto en duda esta interpretación: "Perhaps then this is after all a post-war, not a pre-war scene, and Alcmeon is actually departing not for Thebas, but for exile?".

23 Cf. SOMMERSTEIN (2010: 61-81). El término, un préstamo inspirado en el método investigativo del personaje Sherlock Holmes, refiere a la eliminación de lo imposible para la determinación de lo probable. 
Para avanzar en este terreno nos proponemos, en primer lugar, recorrer el contenido y testimonios existentes del tema del héroe Alcmeón en Esquilo, Sófocles y Eurípides; en segundo lugar, y a partir del relevamiento lexical que comprende los grandes hitos de la vida del héroe, determinar los puntos de anclaje de su biografía trágica. Estos hitos giran a nuestro juicio en torno a los siguientes episodios-ejes, que, pese a la escasez de los fragmentos y los problemas textuales y contextuales de algunos de ellos, nos es posible establecer:

1. la recepción femenina del kósmos en calidad de dôron (el objeto con que es sobornada Erifila);

2. la guerra entre póleis (Argos us. Tebas);

3. el matricidio y la locura de Alcmeón (o la venganza del padre y el castigo materno);

4. el exilio, como punto de finalización y de inicio del peregrinar purificatorio del héroe.

Comencemos por repasar los testimonios, y los datos que es posible conocer sobre las obras. De la tragedia de Esquilo, Epígonos, poco es lo que se puede decir más allá del título, ya que el único fragmento existente proviene de una fuente indirecta (Schol. Pind. Isthm 6.7) ${ }^{24}$. Refiere a una

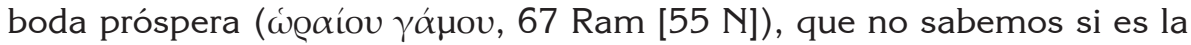
de Alcmeón. Se ha postulado que la tragedia probablemente era la tercera de la tetralogía de la que formaba parte Los siete contra Tebas (RAMELLI, 2009: 633, n. 49). En el caso de Sófocles y Eurípides, en cambio, es posible aventurar con mayor o menor certeza algunos datos más, a partir de dos hechos: la mayor cantidad de fragmentos y la recurrencia del mismo personaje en distintas obras, lo que a priori permite concluir el tratamiento de diferentes segmentos de su historia. Aun así, el número de versos para cada uno de estos autores es poco representativo; se origina en fuentes lexicográficas que han transmitido pasajes muy breves, e incluso de difícil atribución, lo que ha de ser tenido en cuenta al momento de realizar un relevamiento como el que postulamos.

Las tragedias de Sófocles Erifila y Epígonos tomaban con certeza la misma parte del mito; remitirían a la guerra, el matricidio y la locura (se-

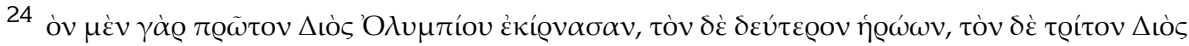

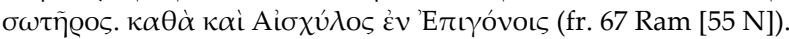

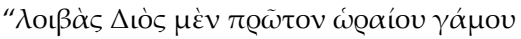

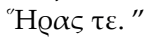

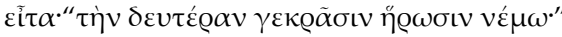

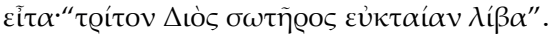

["Pues, la primera crátera que mezclaban era de Zeus Olímpico, la segunda, de los héroes, la tercera, de Zeus Salvador, como dice Esquilo en Epígonos: Por esta boda próspera, en primer lugar, libo a Zeus y a Hera'; después: la segunda libación la cumplo por los héroes'; entonces: la tercera libación votiva, a Zeus Salvador'”].
} 
gún es posible inferir de los frs. 187 y $201 \mathrm{~g} \mathrm{R})^{25}$. Conocemos ahora, a partir de un recientemente descubierto fragmento de papiro (fr. 890+ S), que la obra Epígonos comenzaba antes de que la expedición contra Tebas tuviera lugar ${ }^{26}$. Y hay al menos un fragmento identificado como correspondiente a esta obra (fr. 190 R) que refiere al exilio del héroe de Argos. En cambio, la tragedia Alcmeón se centraría más bien en los episodios posteriores: la locura, el exilio, la estancia en Psófide en busca de su purificación, y el matrimonio con la hija del rey Fegeo. Para las primeras obras, de las que contamos con una treintena de versos, hay coincidencia en señalar una datación temprana, anterior al 430 a.C. (cf. Kiso, 1984; SOMMERSTEIN, 2012). De la última, nada sabemos y son bastante más escasos los fragmentos supérstites: la edición de Radt recoge solo tres (frs. 108-110 R), y dos de ellos están conformados apenas por un término. El más revelador, el fr. $108 \mathrm{R}$, probablemente en boca de Alcmeón, refiere a alguien que es capaz de razonar bien cuando antes no lo era, y confirma, entonces, la presencia del tema de la locura ${ }^{27}$. Con tan poco material, sin embargo, poco es posible conjeturar del contenido del drama. Todo parece indicar que el segmento tratado por Sófocles en Alcmeón podría coincidir en parte con el del primero de los dramas euripideos (Alcmeón en Psófide o Alcmeón A), o, al menos, que difícilmente el poeta tomaría el segmento previo al exilio del héroe de su ciudad, considerando que es el que ya aborda en las otras dos obras.

Con relación a Eurípides, Rachel AÉLION (1983) afirma que fue el poeta trágico que proporcionó el conocimiento más completo (o al menos el más

25 El fragmento 187 es citado por Plutarco en Moralia 35.d-e y 88f-89a:

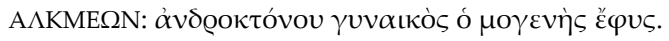

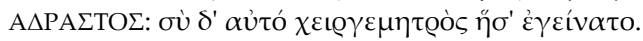

Alcmeón: "Eres el hermano de la mujer que mató a su esposo".

Adrasto: "Y tú, el asesino de la mujer que te engendró".

El fr. 201g, identificado por Clemente de Alejandría como perteneciente a Erifila, es citado en Stromateis 6.2.10.3:

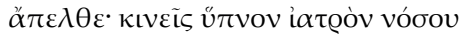

"Vete. Estás alterando el sueño sanador de su enfermedad"

26 Ello permite concluir que la guerra tendría lugar durante el desarrollo de la obra, lo que vuelve a plantear el problema del lugar del matricidio. El fragmento en cuestión es un pasaje anapéstico de un papiro del s. III (Oxyrhynchus Papyrus 4807, publicado por C. MüLKE en 2007), que refiere a la preparación de los armamentos para la guerra, y que permite explicar el fr. $890 \mathrm{R}$, hasta entonces no satisfactoriamente vinculado a Epigonos. SOMMERSTEIN (2012: 38 ss.), que como ya se dijo sostiene la identificación de ambos dramas (Erifila y Epígonos), ha defendido la pertenencia del pasaje a la párodos de la obra y la identidad de un coro constituido por ancianos argivos. Para el texto, remitimos a este autor.

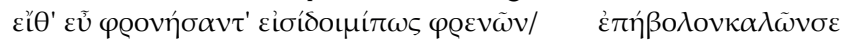

"¡Ojalá pudiera dirigirte la mirada después de haber razonado bien, a ti que estas en posesión de bellos pensamientos!"

El fragmento es citado por Porfirio (Quaest. Hom II. 283): 
extenso) del Ciclo Tebano; sin embargo, Anfiarao y Erifila ingresan muy tangencialmente a los dos dramas que protagoniza su hijo ${ }^{28}$. Ambas obras euripideas - Alcmeón en Psófide (A) y Alcmeón en Corinto (B) - refieren a las vicisitudes del héroe derivadas de sus sucesivos matrimonios como exiliado de Argos, y guardan entre sí una relación que, como se ha señalado, resulta bastante laxa. Pocos elementos proporcionan sobre las dos cuestiones planteadas de la locura y el matricidio. Sobre todo, los escasos fragmentos impiden afirmar la posibilidad de una escena del protagonista en estado de manía que testimonia el pasaje del apologista asirio Taciano en Oratio ad Graecos 24 (s. II d.C.) ${ }^{29}$. En cambio, a juzgar por lo que permite la reconstrucción de cada una de las tramas, el lugar central en ellas reside en la solidaridad familiar y los riesgos de las uniones matrimoniales de Alcmeón, que ponen al descubierto el conflicto de lealtades entre oîkos natal y oîkos conyugal, y permiten advertir una temática común, por sobre la relación superficial que existe entre las tragedias.

La historia de Alcmeón en Psófide es contada por Apolodoro (Apolodoro 3.6.2 y 3.7.2 ss.) y, con algunas diferencias, por Pausanias (8.24.8): Alcmeón, perseguido por las Erinias de su madre asesinada, se exilia primero en Arcadia junto a Oícles y luego en Psófide, donde es purificado por Fegeo, y se casa con su hija, Arsínoe (Apolodoro)/Alfesibea(Pausanias). Pero una peste comienza a asolar la ciudad y Alcmeón, guiado por el oráculo, debe ser nuevamente purificado, ahora por Aqueloo, con cuya hija Calírroe se casa. Esta demanda también el collar de Harmonía. Alcmeón retorna a Psófide en su búsqueda, alegando que solo será purificado si lo dedica como ofrenda en Delfos. Delatado ante Fegeo que el collar era para Calírroe, este ordena a sus hijos la emboscada que da finalmente muerte a Alcmeón ${ }^{30}$.

28 De hecho, esta autora excluye el tratamiento del mito de Alcmeón en su análisis del Ciclo Tebano, por considerar que, a excepción del episodio del collar de Erifila (1983: 92), el mito de Alcmeón no forma parte del dicho Ciclo.

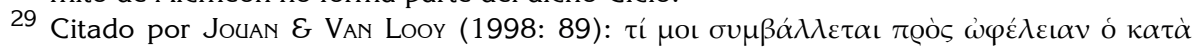

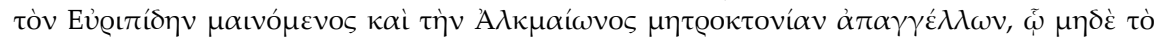

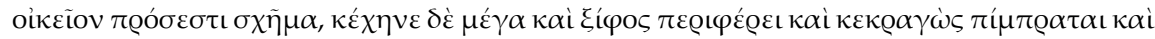

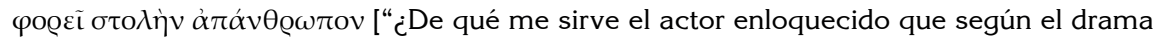
de Eurípides refiere el matricido de Alcmeón, quien no tiene un aspecto ordinario, abre grandemente la boca, blande la espada, grita y se enciende, y lleva vestimenta salvaje?"]. Uno de los problemas fundamentales que ha planteado esta obra es el punto de comienzo de la historia. Las posiciones se han dividido entre quienes consideran que el drama comenzaría con la primera llegada de Alcmeón a Psófide buscando purificación, lo que implicaría un intervalo temporal bastante extenso hasta su muerte, y quienes consideran que comenzaba con el segundo arribo de Alcmeón para recuperar el collar. JouAN $\mathcal{E}$ VAN Looy (1998: 95-98) dejan la cuestión abierta. Cf. MEDDA (2001: 66, n. 79), para las referencias de las diferentes posiciones. 
A pesar del doble testimonio de Apolodoro y Pausanias, la trama del más antiguo de los dramas euripideos es, sin embargo, la más difícil de reconstruir: por el largo segmento témporo-espacical que supone, y porque no pocos de los fragmentos conservados nos han llegado citados en los distintos testimonios bajo el título genérico de Alcmeón (lo que hace difícil la atribución a una u otra tragedia) ${ }^{31}$. La escena de locura, de haber tenido lugar en este drama, podría haber sucedido verosímilmente durante la primera o la segunda ida de Alcmeón a Psófide, pues en cualquier caso cada uno de estos viajes supone la necesaria purificación del crimen co-

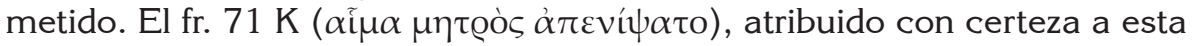
tragedia, podría remitir a un ataque alucinatorio en que Alcmeón estuviera viendo a su madre, aunque el contexto y lo problemático del texto de este verso, una vez más, no permiten ninguna conclusión ${ }^{32}$. En todo caso, la necesidad de certeza sobre este tema proviene de la significación que adquiriría de haber tenido lugar una escena de locura en una tragedia treinta años anterior a Orestes (408 a.C.), donde las alucinaciones de un matricida son experimentadas y descritas en el drama por el propio enfermo, como señalara Enrico MEDDA (2001: 62-73).

Para la trama de Alcmeón en Corinto, en cambio, la propia narración de Apolodoro 3.7 cita a Eurípides como fuente ${ }^{33}$. El drama remite a la historia los hijos de Manto con Alcmeón, su entrega y posterior rescate. Los

31 Acerca de los fragmentos existentes, en la edición de KANNICHT, siete fragmentos son asignados a Alcmeón en Psófide o Alcmeón A (fr. 65, 66, *69, *70, 71, 72 y 73), cinco a Alcmeón en Corinto o Alcmeón B (73a, 74, 75, *76, 77), en tanto doce fragmentos son inciertos, y podrían corresponder a una u otra tragedia $(78,78 a, 79,80,81,82,83,84$, $85,86,87,87 a)$. Otro problema es el título mismo de la obra, que registra en las fuentes antiguas y bizantinas las variantes $\mathrm{A} \lambda \kappa \mu \alpha i ́ \omega \nu$ y $\mathrm{A} \lambda \kappa \mu \varepsilon \dot{c} \omega \nu$.

32 Para Webster (1967 este fragmento) debe pertenecer al prólogo de Alcmeón en Psófide, y lo considera clave para definir el momento de la acción: la segunda llegada de Alcmeón a Psófide. Incluye, en la edición de KanNicht (2004) y en la de Collard (2008), la variante que elimina el vocativo problemático $\mu \tilde{\eta} \tau \varepsilon \varrho$ de la edición de NАuск(justificado asimismo por Webster como un vocativo emocional por el que Alcmeón se estaría lamentando, al volver a Psófide, de engañar a un hombre con quien tendría que estar agradecido).

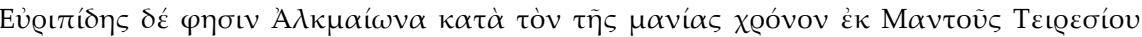

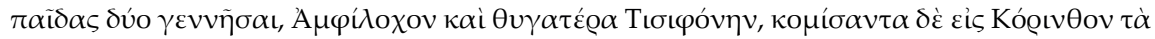

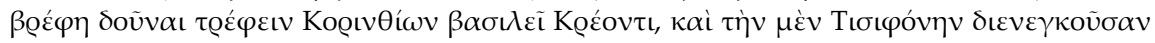

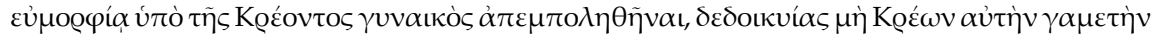

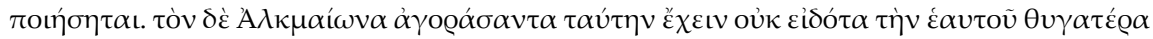

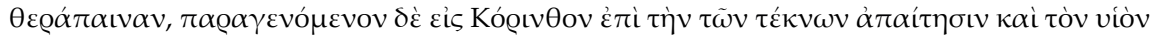

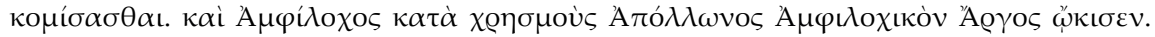
["Eurípides afirma que Alcmeón durante el tiempo de su locura tuvo dos hijos de Manto, la hija de Tiresias, Anfíloco y una hija, Tisífone, y que habiendo llevado a sus vástagos a Corinto, se los dio al rey Creonte para que los criara. Tisífone, que destacaba por su belleza, fue vendida como esclava por la esposa de Creonte, pues temía que este la hiciera su esposa. Pero Alcmeón, tras comprarla, la tenía con él sin saber que la servidora era su 
episodios son naturalmente anteriores a la historia de Alcmeón en Psófide, pero inmediatamente posteriores al triunfo de los Epígonos sobre Tebas, pues Manto es el más preciado botín de guerra asignado al jefe argivo de la expedición después de la toma de la ciudad. Apolodoro señala explíci-

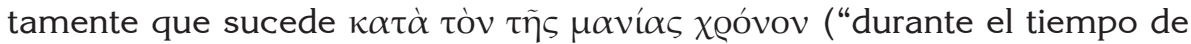
su locura").

El tratamiento del motivo de la purificación del matricida es en este drama sustancialmente diferente, desde el momento en que, lejos de tematizar la mancha y el castigo de Alcmeón, el final afirma el vínculo entre Anfíloco, su hijo, y Argos de Anfiloquia. Un análisis reciente de Sonia FranCISETTI BRolin (2013) ha puesto de relieve que ello obedece a una suerte de mitología política euripidea, en la que el tema de la locura y el matricidio son desplazados por la centralidad que adquiere el futuro del héroe y su génos. De cualquier modo, la referencia de Apolodoro, y la única fuente iconográfica sobre la presencia de Alcmeón en Corinto no permiten desestimar completamente la existencia de una escena de locura en la obra, hipótesis que WEBSTER (1967: 265-268) defendió como modelo inspirador de la posterior tragedia latina de Ennio ${ }^{34}$.

Hasta aquí el tema de cada una de las obras perdidas. En cuanto al relevamiento lexical, este permite ser sintetizado en el siguiente cuadro, para cuya interpretación conviene, sin embargo, tener presente algunos puntos ya señalados que recordaremos aquí:

a) la diferencia en extensión de los testimonios conservados para cada uno de los autores;

b) la exclusión de Esquilo, por la escasez e incertidumbre que plantea el único fragmento conservado;

c) la posible identificación de las obras Epígonos y Erifila en el caso de Sófocles;

d) la dificultad de atribuir los fragmentos a una u otra obra con relación a Alcmeón en Psófide (A) y Alcmeón en Corinto (B) de Eurípides ${ }^{35}$.

propia hija. Y cuando se presentó en Corinto para reclamar a sus hijos, se llevó también al hijo. Y Anfíloco, de acuerdo con el oráculo de Apolo, fundó Argos Anfilóquico."].

34 Con relación a esta única fuente iconográfica, se trata de la crátera apulia de volutas (Vat. AA2, ca. 350 a.C.), del pintor de Licurgo. Es el único testimonio mencionado en el LIMC de la presencia de Alcmeón en Corinto: una doncella y un hombre mayor sentados ante un altar como suplicantes; a la derecha, un rey que lleva un cetro y que se aproxima; a la izquierda, un hombre más joven con dos lanzas. Junto al altar, una palma; más a la derecha un laurel. La identificación de estos personajes, como de los de la línea superior (entre los que se encuentra una Erinia) no es clara.

35 Los fragmentos incluidos en el cuadro han sido citados siguiendo la convencional numeración de los TrGF; los fragmentos sofocleos incluyen, sin embargo, algunas de las variantes textuales y el texto adicional (fr. 890+) consignados en la edición de SOMMERTEINS (2012), en cuyo caso se los ha identificado con la inicial del editor (S). 


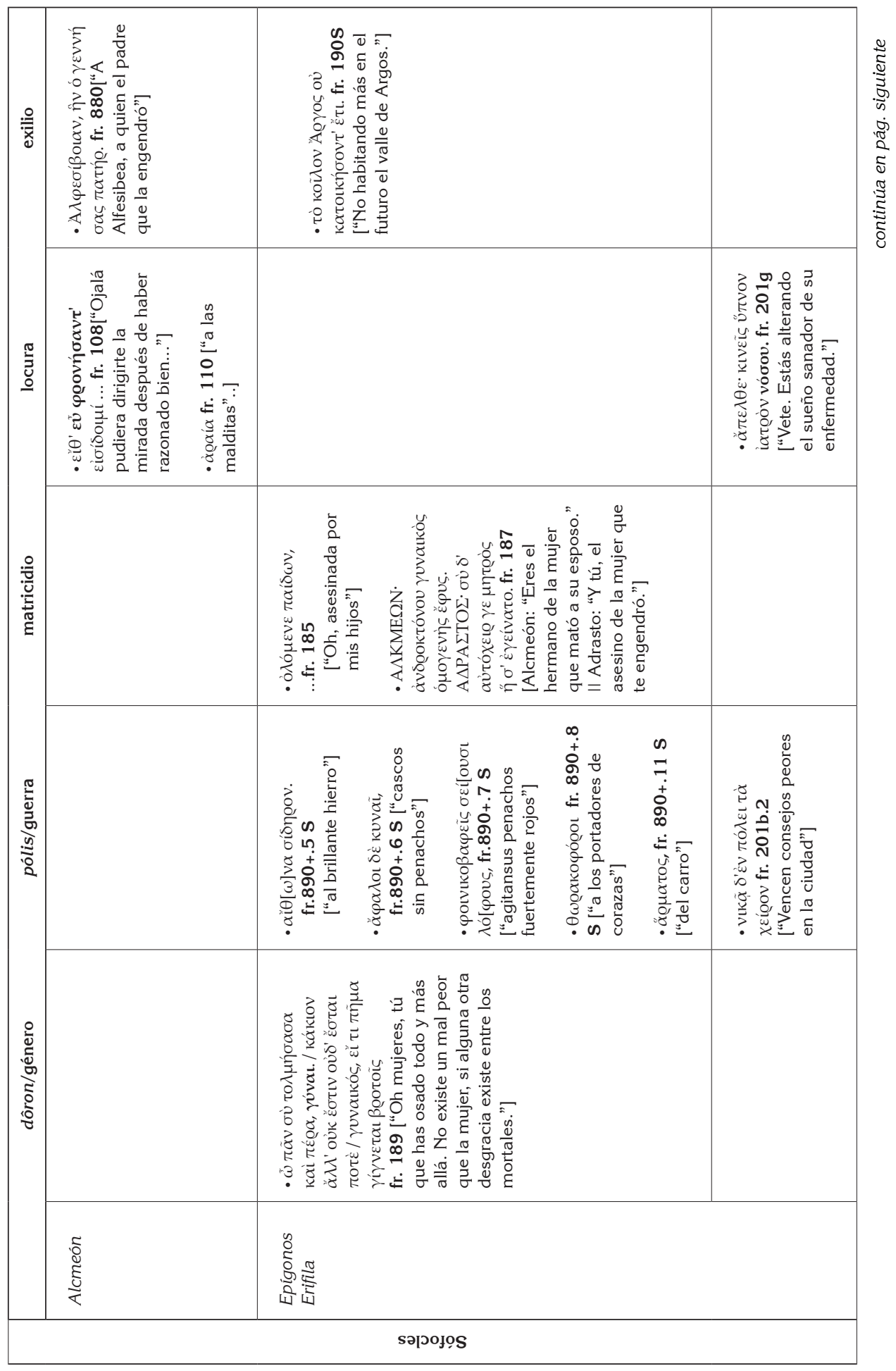




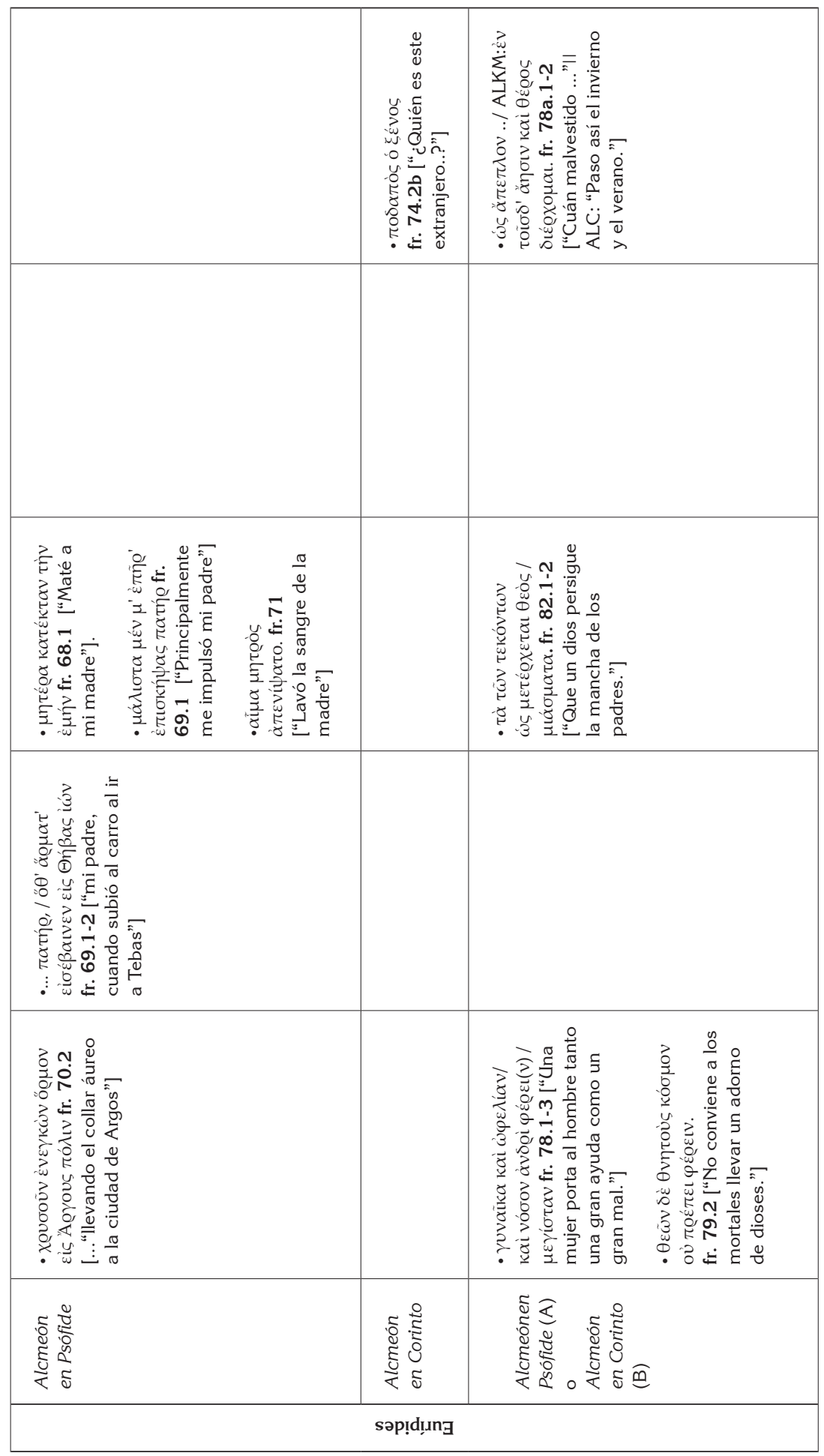


¿Qué es posible concluir de ello, entonces, más allá de lo hasta aquí señalado? El relevamiento lexical nos habla de la pérdida, que es cuantiosa, del olvido, que es grande; pero también habla de la memoria, de aquello por lo que Alcmeón, el jefe argivo tan largamente abandonado, no pudo desaparecer completamente: su lugar en la historia de uno de los paradigmáticos matricidas. En un punto, pues, reflexionar sobre esta historia "trágica", superando las incertidumbres y las especulaciones que concita, no es sino una invitación a devolver una nueva mirada a la tragedia; una mirada escéptica a la memoria de las historias que se han conservado, a la par que una mirada inquisidora hacia aquellas que se han perdido.

\section{Bibliografía}

\section{Ediciones}

Collard, C., Cropp, M. J. \& Lee, K. H.(eds.) (1995) Euripides: Selected Fragmentary Plays, vol. I, Warminster.

Collard, C., Cropp, M. J. E Gibert, J. (eds.) (2004) Euripides: Selected Fragmentary Plays, vol. II, Oxford.

Collard, C. E Cropp, M. J. (eds.) (2008a) Euripides: Fragments, VII.1, Aegeus-Meleager, LCL. Cambridge, MA.

Collard, C. E Cropp, M. J. (eds.) (2008b) Euripides: Fragments, VII.2 Oedipus-Chrysippus. LCL. Cambridge, MA.

Diggle, J. (ed.) (1982-94) Euripidis. Fabulae, I-III, Oxford.

(1994) Euripidea: Collected Essays, Oxford.

Jouan, F. E van Looy, H. (eds.) (1998-2003) Euripide. Tragédies. Fragments.

T. VIII (1 ere $^{\text {- }}{ }^{\text {ème }}$ partie), Paris.

Kannicht, R. (ed.) (2004) Tragicorum Graecorum Fragmenta, vol. 5, Göttingen.

Nauck, A. (ed.) (1964) Tragicorum Graecorum Fragmenta, with Supplementum by B. Snell, Hildesheim.

RADT, S.L. (ed.) (1999²) Tragicorum Graecorum Fragmenta, Vol. 4: Sophocles, Göttingen [1977].

Ramelli, I. (ed.) (2009) Eschilo. Tutti i frammenti con la prima traduzione degli scolii antichi, intr., trad, note e apparati di Ilaria Ramelli, Milano.

Sommerstein, A. H., Fitzpatrick, D. E Talboy, T. (eds.) (2006) Sophocles: Selected Fragmentary Plays, Volume I, Oxford. 
Sommerstein, A. H. E Talboy, T. (eds.) (2012) Sophocles: Selected Fragmentary Plays, Volume II, Oxford.

Thesaurus Linguae Graecae (2000) a Digital Library of Greek Literature, Irvine, CA. Versión E [CD ROM], University of California,.

Bibliografía crítica general

AÉLION, R. (1983) Euripide héritier d'Eschyle, Paris.

_ (1986) Quelques grands mythes héroïques dans l'oeuvre d'Euripide, Paris.

BALmer, J. (2013) Piecing Together the Fragments, Oxford.

Belfiore, E.S. (2000) Murder among Friends. Violation of Philia in Greek Tragedy, New York \& Oxford.

Bushnell, R. (ed.) (2005) A Companion to Tragedy, India,Oxford \& USA.

CARrara, P. (2009) Il testo di Euripide nell'Antichità, Firenze.

Collard, C. (2005) "Euripidean Fragmentary Plays: the Nature of Sources and their Effect on Reconstruction", en F. McHardy etal. (eds.), Lost Dramas of Classical Athens: Greek Tragic Fragments, Exeter, pp. 49-62.

Cousland, J.R.C. \& Hume, J.R. (eds.) (2009) The Play of Texts and Fragments. Essays in honour to Martin Cropp, Leiden.

Cropp, M.(2005) "Lost Tragedies: A Survey",en J. Gregory(ed.),A Companion to Greek Tragedy, London,pp. 271-292.

Cropp, M.J., Lee, K. \& SAnsone, D. (eds.) (2000) Euripides and Tragic Theatre in the Late Fifth Century, Illinois.

Cropp, M.J. \& Fick, K. (1985) Resolutions and Chronology in Euripides. The Fragmentary Tragedies, BICS. Suppl. 43, London.

Csapo, E. E Slater, W. J. (eds.) (1994) The Context of Ancient Drama, Ann Arbor.

Delcourt, M. (1959) Oreste et Alcméon. Étude sur la projection légendaire du matricide en Grèce, Paris.

Debiasi, A. (2015) "The Alcmeonis between the Theban and the Trojan Cycle”, en M. FantuzziE Ch. Tsagalis (eds.) The Greek Epic Cycle and Its Ancient Reception: A Companion, Cambridge, pp. 261-280.

Del Rincón Sánchez, F.M. (2007) Trágicos menores del siglo Va.C. (de Tespis a Neofrón): estudio filológico y literario, Madrid.

FrancisetTI Brolin, S. (2013) "Sul mito tragico di Alcmeone: la mitologia politica di un secondo Oreste", Atti dell'Accademia delle Scienze di Torino, Classe di Scienze Morali, Storiche e Filologiche 147, pp. 73-84. 
García Gual, C. (1991) "Tradición mítica y versiones trágicas: la venganza de Alcmeón”, Analecta Malacitana14, pp. 5-18.

- (2014) La venganza de Alcmeón. Un mito olvidado, Madrid.

Gregory, J. (ed.) (2005) A Companion to Greek Tragedy, London.

Hall, E. (2010) Greek Tragedy. Suffering under the Sun, Oxford.

Kiso, A. (1984) The Lost Sophocles, New York.

KRAuSKOPF, I. (1981) "Amphiaraos" y"Alkmaion", en LIMC I, Zurich-Munich, pp. 691-717 y pp. 546-552.

(2000) "I miti tebani nell'iconografia di altre regioni greche", en:Presenza e funzione della città di Tebe nella cultura greca, Atti del Convegno Internazionale Urbino7-9.7.1997, Pisa - Roma, pp. 291-315.

Lens Tuero, J. (1980) "La reconstrucción de tragedias griegas perdidas, I: Los materiales". Sodalitas I, pp. 85-112.

LuCAS DE DIOS, J.M. (1990) "La tragedia griega. Una valoración de conjunto", Epos 6: 37-49.

McHardy, F. -Robson, J. EHarvey,D. (eds.) (2005) Lost Dramas of Classical Athens: Greek Tragic Fragments, Exeter.

Medda, E. (2001) Euripide. Oreste, Milano.

Mills, S. (2003) “'Sophocles' Aegeus and Phaedra”, en A. H. Sommertein (ed.), Shards rom Kolonos, Bari, pp. 219-240.

Most, G. (2009) "On fragments", en W. Tronzo (ed.), The Fragment: An Incomplete History, Getty Research Institute,pp. 9-22.

Revermann, M. (ed.) (2010) Beyond the Fifth Century: Interactions with Greek Tragedy from the Fourth Century BCE to the Middle Ages, Berlin ENew York.

SCHADEWALDT, W. (1952) "Zu einem Florentiner Papyrusbruchstück aus dem Alkmeon in Psophis des Euripides", Hermes 80, pp. 46-66.

SommerStein, A. H. et al. (eds.) (1993) Tragedy, Comedy and the Polis, Bari. SommerStein, A. H. (ed.) (2003) Shards from Kolonos: Studies in Sophoclean Fragments, Bari.

(2010) The Tangled Ways of Zeus: And Other Studies In and Around Greek Tragedy, Oxford.

TApuIN, O. (1993) Comic Angels, and other approaches to Greek Drama through vase-painting, Oxford.

- (2007), Pots E Plays, Oxford.

Varias García, C. (1998) "Testimonios de Orestes y de Alcmeón antes de Esquilo”, en: F. Rodríguez Adrados \& A. Martínez Diez(eds.), Actas del IX Congreso Español de Estudios Clásicos (Madrid, 27 al 30 de septiembre de 1995), vol.iv, Madrid. 
WeBster, T. B. L. (1967) The Tragedies of Euripides, London.

WiLES, D. (2005) "HY] [ YLE. A Version for the Stage", en F. McHardy et al.(eds.), Lost Dramas of Classical Athens: Greek Tragic Fragments, Exeter, pp. 189-207.

Wright, M. (2016) The Lost Plays of Greek Tragedy, vol. 1. Neglected Authors, London, Oxford, New York, New Delhi ESidney.

Sitio Web

Lost Greek Plays. Performing the Fragments of Ancient Dramas<http:// lostgreekplays.com> [consultado: 1 de abril de 2018].

Fecha de recepción: 15-05-2018

Fecha de aceptación: 10-09-2018 